\title{
LA IMPORTANCIA DE LA PEDAGOGÍA COMO HERRAMIENTA DE CONSTRUCCIÓN Y VALIDACIÓN DE LAS INSTITUCIONES PÚBLICAS, DEL DERECHO PÚBLICO Y DEL DERECHO PÚBLICO INTERNACIONAL
}

\author{
THE IMPORTANCE OF PEDAGOGY AS A TOOL FOR THE \\ CONSTRUCTION AND VALIDATION OF PUBLIC INSTITUTIONS, \\ PUBLIC LAW AND INTERNATIONAL PUBLIC LAW \\ A IMPORTÂNCIA DA PEDAGOGIA COMO FERRAMENTA DE \\ CONSTRUÇÃO E VALIDAÇÃO DAS INSTITUIÇÕES PÚBLICAS, DO \\ DIREITO PÚBLICO E DO DIREITO INTERNACIONAL PÚBLICO
}

$$
\text { Jonatan Alexis Agudelo Bran* }
$$

Recibido: 30 de noviembre de 2020 - Aceptado: 30 de mayo de 2021-

Publicado: 30 de junio de 2021

DOI:

\section{Resumen}

El presente artículo busca evidenciar el arquetipo general de Colombia, sus condiciones materiales y la importancia de analizar sus contextos, generando una inquietud sobre las instituciones públicas, el

Estudiante de Ciencias Políticas, Universidad Nacional de Colombia, Sede Medellín. CvLAC: https://scienti.minciencias.gov.co/cvlac/visualizador/generarCurriculoCv.do?cod_rh=0001835589; ORCID: https://orcid.org/0000-0002-3253-9057; Google Scholar: https://scholar.google.es/citations?hl=es\&user=SPIpwb4AAAAJ\&scilu. Correo electrónico: joagudelob@unal.edu.co 
derecho público y el derecho público internacional, con temas transversales que permitirán reconocer una realidad que nos configura de forma directa o indirecta. Para abordar tal planteamiento se hizo uso de la revisión documental como principal técnica de investigación. Se analizaron artículos, sentencias y libros, retomando pensadores como Aristóteles, Rousseau, Kant, Goethe, entre otros. A partir de este análisis, se identifica la inquietud como herramienta de reflexión para revisar la construcción del individuo, su colectividad y el desarrollo de los mecanismos que lo configuran de forma directa o indirecta, ya que el individuo es un ciudadano en potencia porque es un contratante de un Estado-Nación. De ahí la importancia de la pedagogía como herramienta de construcción y de validación de dichos mecanismos, puesto son los que permiten que los individuos no solo los asuman y los conozcan, sino que los puedan interpretar y decidir sobre estos.

Palabras clave: pedagogía, ciudadanía, institución, derecho, público.

\section{Abstract}

This article seeks to show the general archetype of Colombia, its material conditions and the importance of analyzing its contexts, generating a concern about public institutions, public law and international public law, with cross-cutting themes that will allow us to recognize a reality that configures us directly or indirectly. To address this approach, document review was used as the main research technique. Articles, sentences and books were analyzed, taking up thinkers such as Aristotle, Rousseau, Kant, Goethe, among others. From this analysis, concern is identified as a tool for reflection to review the construction of the individual, his community and the development of the mechanisms that configure him directly or indirectly, since the individual is a potential citizen because he is a contracting party of a nation-state. Hence the importance of pedagogy as a tool for the construction and validation of these mechanisms, since they are what allow individuals not only to assume and know them, but to be able to interpret and decide on them.

Keywords: Pedagogy, citizenship, institution, right, public. 
La importancia de la pedagogía como herramienta de construcción y validación de las instituciones públicas, del derecho público y del derecho público internacional

\section{Resumo}

Este artigo busca mostrar o arquétipo geral da Colômbia, suas condições materiais e a importância de analisar seus contextos, gerando uma preocupação sobre as instituições públicas, o direito público e o direito internacional público, com temas transversais que nos permitirão reconhecer uma realidade que nos configura direta ou indiretamente. Para abordar essa abordagem, a revisão de documentos foi usada como a principal técnica de pesquisa. Foram analisados artigos, frases e livros, retomando pensadores como Aristóteles, Rousseau, Kant, Goethe, entre outros. A partir dessa análise, identifica-se a preocupação como instrumento de reflexão para rever a construção do indivíduo, de sua comunidade e o desenvolvimento dos mecanismos que o configuram direta ou indiretamente, visto que o indivíduo é um cidadão potencial por ser parte contratante de uma Estado-nação. Daí a importância da pedagogia como instrumento de construção e validação desses mecanismos, pois são eles que permitem aos indivíduos não só assumi-los e conhecê-los, mas também interpretá-los e decidi-los.

Palavras-chave: Pedagogía, cidadania, instituição, direito, público. 
En 1620, Francis Bacon publicó un manifiesto titulado Novum Organum. En él razonaba que "Saber es poder"

(Harari, 2014, p. 288)

\section{INTRODUCCIÓN}

Cuando se habla de la ciudadanía y su proceso de civilización en el Estado Social de Derecho, se habla de convenios, regulación e institucionalización, es decir, de instituciones públicas, derecho público y derecho público internacional; con esto surgen algunas preguntas fundamentales: ¿cómo aparecieron?, ¿eso existe?, ¿por qué es de desconocimiento general?, ¿por qué, en pleno siglo XXI, aún no se ha masificado tales tópicos en la sociedad de forma universal? Para responderlas no hay que ir muy lejos, pues Colombia sirve como respuesta.

Para entender el párrafo anterior, es necesario hacer una radiografía general de Colombia que nos permitirá analizar las particularidades de estas preguntas. Dos fuentes serán referenciadas para el desarrollo del texto, la primera es el referendo del 2003 conocida como La ciudadana Maria del Carmen Reyes y la segunda las votaciones presidenciales del 2018 realizadas por CELAG, dichas fuentes servirán para analizar el contexto colombiano con la hipótesis que los ciudadanos tienen desconocimiento de los mecanismos de participación y por consiguiente de las instituciones públicas como del derecho público; ya que los mecanismos de votación y referendo son los más visibles y generales en el desarrollo del Estado Social de Derecho colombiano.

Como primer panorama se encuentra, en el 2003, el ejemplo de María Carmen, un arquetipo general colombiano que no solo se ve en la ruralidad, sino también en lo urbano. Carlos Gaviria (2003) hace una descripción sobre la ignorancia — desinformación — que vive María Carmen en su día a día:

María del Carmen Reyes, que demoró treinta y cinco minutos votando el Referendo. No tiene televisión, no lee prensa, no tiene tiempo ni ganas de concurrir a convites de adoctrinamiento político, no cree que quienes la gobiernan puedan utilizarla o engañarla, concurre a las urnas y se enfrenta sola, sorprendida y angustiada, con las preguntas del Referendo. Solo la asisten su buena voluntad y su conciencia incontaminada. Sale del cubículo extenuada y al preguntársele por qué tardó allí tanto tiempo, responde: estaba tratando de entender, pero fue muy poco lo que conseguí (p. 1). 
La importancia de la pedagogía como herramienta de construcción y validación de las instituciones públicas, del derecho público y del derecho público internacional

Es importante mencionar el artículo periodístico de Gaviria a la par que El contrato social de Rousseau como fuentes sólidas hacia la construcción de la democracia y sus principios regidores para que esta funcione; dichos principios son la decisión y el interés de las relaciones recíprocas (Estado-ciudadanía) que permiten conciliar un principio implícito y necesario, el de la cultura ciudadana, esa de reconocer los intereses regidores, sus mecanismos e instituciones que los representan y que reflejan las realidades de una sociedad.

En el texto de Gaviria se pueden observar unas inquietudes implícitas, es decir, hay unas realidades que deben ser reconocidas para analizar la construcción y la validación de estas instituciones y mecanismos; por lo tanto, se mencionan dos aspectos: el primero, la coacción de la decisión de forma directa e indirecta, y el segundo, y el más importante, la desinformación latente y el analfabetismo político e histórico que, a su vez, es agravado por las condiciones materiales de los colombianos en el tópico de la configuración (Estado-Nación), sistema político, como regidores de la vida ciudadana. Estos aspectos se profundizarán más adelante.

En ese orden de ideas, el texto enunciado se ve fortalecido con un estudio del 2018, quince años después de la escritura de "La ciudadana María del Carmen Reyes" (Gaviria, 2003), que, aunque no tenga orígenes iguales — valga la aclaración-, cuenta con circunstancias similares.

En el estudio hecho por Navarro y Fierro (2018), se realizó una encuesta sobre las elecciones presidenciales del 2018 en Colombia, por ende, del sistema electoral, a un grupo significativo de personas de todos los estratos socioeconómicos. La discusión estuvo dirigida a los rumores, los juicios de valor, la economía, las políticas discursivas y los personajes; sin embargo, no se orientó hacia las instituciones públicas.

Incluso, los encuestadores se vieron obligados a insertar en la discusión, de forma explícita, la importancia de la votación para poder elaborar las preguntas pertinentes de la encuesta, ya que las personas no iban al punto que apremiaba en el 2018, que era el ejercicio de "elegir y ser elegido", encargado por la institución del Centro Nacional Electoral (CNE). Como resultado, afirmaron y determinaron que "cualquier conclusión posterior de este estudio cualitativo debe ser analizada a la luz de la premisa del desinterés y desinformación sobre las elecciones" (Navarro y Fierro, 2018, p. 1). ¿Por qué se exponen el artículo y la encuesta? 
Para la inquietud anterior se expresó una razón relevante: el desconocimiento, la desinformación y la coacción directa e indirecta de los ciudadanos a la hora de reconocer las instituciones públicas, el derecho público y el derecho público internacional como regidores de la cotidianidad. Pues al no aceptar al sistema electoral se puede extrapolar que la situación de las tres instancias mencionadas, que son menos populares, no es de interés general y, por ende, son relegadas al olvido. ¿Pero este análisis solo basta con la óptica del desinterés? La respuesta es no, ya que para llegar al fenómeno no se puede asumir como espontáneo, por el contrario, es un hecho que históricamente se ha elaborado y construido.

Para desarrollar tal idea, se iniciará con un desliz técnico, ya que la pedagogía indica hacerlo, pues el objetivo del trabajo es generar inquietud para traducir la ciencia a la gente, en este caso, las instituciones y el derecho público.

Cuando se lee acerca de la dialéctica materialista (Stalin, 1977), se puede asumir una postura de contradicciones sobre la construcción del conocimiento con base en lo tangible (materia) ${ }^{1}$ que, a su vez, se transforma en intangible por la conciencia transformadora de su alrededor; cuando se hace tal aproximación, se debe enfocar la configuración social como un andamiaje de aspectos históricos que se viven por y con las condiciones materiales del sujeto y su entorno.

Ahora bien, el ser humano, cuando inicia su tránsito a la juventud y posterior a ella a la adultez (se va convirtiendo en ciudadano), emprende y construye una conciencia con base en las experiencias que este tiene en su espacio-tiempo, por la interacción de actores/agentes/entornos tangibles o intangibles. Este fenómeno lo podemos denominar construcción de conocimiento.

1 Principios fundamentales del materialismo filosófico marxista: 1) el mundo es material y se desarrolla según las leyes del movimiento de la materia; 2) la materia es anterior a la conciencia y 3) el mundo material y sus leyes son cognoscibles, y las verdades científicas son objetivas. El materialismo filosófico marxista sostiene que el mundo es material por naturaleza y que los diferentes fenómenos son formas diversas de la materia en movimiento. El materialismo marxista prueba que todos los cuerpos, desde las ínfimas partículas del átomo hasta los gigantescos planetas, desde las bacterias hasta los animales superiores, hasta el hombre, son la materia bajo sus diferentes formas y en sus diversas etapas de desarrollo. Contrariamente al idealismo, que considera que el mundo es creado por Dios o que es una encarnación de la "idea absoluta", del "espíritu universal", de la "conciencia", el materialismo filosófico marxista sostiene que la materia existe eternamente, que no ha sido ni es creada por nadie, que el mundo se desarrolla según las leyes objetivas del movimiento de la materia y no tiene necesidad de ningún "espíritu universal" (Rosental \& Iudin, 1959, p. 323). 
La importancia de la pedagogía como herramienta de construcción y validación de las instituciones públicas, del derecho público y del derecho público internacional

La importancia de entender este fenómeno de construcción de conocimiento es observar y analizar este proceso en las configuraciones sociales: pues se parte del que el individuo es un sujeto natural y artificial que se da por la sociedad y la sociedad de esté, por ende, se comprende que de este proceso circular de materia y conciencia esté concede en una conciencia colectiva. Conciencia que se desarrolla por medio de interacciones del entorno interno y externo. Evolucionando y transformando esa conciencia debido a las relaciones y los comportamientos a la necesidad individual o colectiva.

El desarrollo conceptual de la conciencia que se propone en cuestión de la dialéctica materialista se debe dar bajo la luz del proceso histórico y contextos sociales, políticos, económicos, entre otros. Por eso, el esbozo del feudalismo hasta la modernidad es menester en este texto para comprender el panorama de Colombia en cuestión de dependencia y relaciones para la construcción del arquetipo colombiano.

Cuando el feudalismo cae se inician nuevas configuraciones en el globo terráqueo occidental; al transcurrir los siglos hubo una mayor influencia, en el siglo XIX y XX, sobre las configuraciones sociales (unas demócratas [Estados Unidos], otras republicanas, desde la aristocracia [Francia, España, entre otras], y, por consiguiente, en el tiempo, otras anarquistas [Comuna de París] o socialistas [Alemania, Rusia]) que generaron una amalgama de múltiples realidades externas que, directa e indirectamente, tuvieron injerencia en Colombia para establecerse como Estado-Nación.

Colombia ha tenido, históricamente, profundas crisis en la construcción de sus experiencias (identidad) y de su organización territorial, por su origen y su desarrollo - desde su descubrimiento (1492) hasta el presente año (2020)—, que se ha ido visibilizando con el tiempo en sus instituciones y en su ciudadanía.

Mientras todo esto ocurría, el país se construyó en medio de conflictos bélicos; sin embargo, dichas circunstancias no le impidieron asumir el proyecto dirigido a la democracia, pero ¿cuál fue el resultado? La inestabilidad en la configuración nacional, desde su inicio, en las líneas estratégicas y fundamentales como la economía, la política, la educación y el contexto social en orden ascendente, por cuestión de relevancia, ocasionando turbulencias a lo largo de la historia, costándole a los habitantes su construcción como ciudadanos. Estos sucesos se retratan en los libros Historia mínima de Colombia (Melo, 2017) y Colombia siglo XX (Ocampo, 2013). 
A Colombia le costó estragos en la economía, debido que para independizarse del yugo español consiguió e incrementó las deudas, por consiguiente, definió su dependencia monetaria con los países europeos para conformar la Gran Colombia (1819-1831) que tuvo unas divisiones en la modernidad denominadas Nueva Granada (1832-1861), Confederación Granadina (1862-1863) y Estados Unidos de Colombia (1863-1886); ya entrados en el siglo XX se identifica como República de Colombia (1886- vigente) y adquiere deudas de gran monto con otros países (Estados Unidos, por ejemplo) e instituciones multilaterales (el Fondo Monetario Internacional, el Banco Interamericano de Desarrollo y el Banco Mundial) que influenciaron y determinaron la toma de decisiones en aspectos políticos hacia la configuración del Estado-Nación, haciendo que el país no sea independiente. Esta realidad se puede notar en El TLC recoloniza a Colombia. Acusación a Álvaro Uribe Vélez (Robledo, 2017), en donde se analizan los Tratados de Libre Comercio (TLC) y el desmantelamiento de la industria nacional que generaron una gran tasa de desempleo y una derrama económica, dando como resultado que la mayoría de los ciudadanos no puedan acceder a las garantías mínimas, viviendo en una constante hostilidad e incapacidad para lograr las habilidades necesarias que les permitan desempeñarse como verdaderos ciudadanos.

Lo anterior se puede referenciar con Aristóteles (1996), quien dice: "Allí la virtud del ciudadano, tal como la hemos explicado, debe entenderse propia, no de todos los hombres, sino de los hombres libres, es decir, de todos los que no necesitan trabajar para vivir" (p. 92). Aunque la referencia sea anacrónica se puede aproximar a las necesidades mínimas del ciudadano, ya que estos deben tener unas condiciones adecuadas para poder formarse y desarrollar la capacidad intelectual que se da por medio de diversos elementos y fenómenos como la alimentación, el entorno en el que se habita, la educación, el tiempo de ocio y los recursos para poder solventar sus necesidades. Cabe resaltar que Rousseau (2018) anunciaba un factor importante, "que ningún ciudadano sea lo bastante opulento para poder comprar a otro y ninguno lo bastante pobre para tener que venderse" (p. 107). Y eso se logra garantizando los mínimos vitales para crear estructuras sólidas.

Aunque el mínimo vital se componga, inevitablemente, de aspectos económicos, no puede ser entendido bajo una noción netamente monetaria. No se protege solo con un ingreso económico mensual. Este debe tener la capacidad de producir efectos reales en las condiciones de la persona, de tal manera que no solo le garantice vivir dignamente, sino también desarro- 
La importancia de la pedagogía como herramienta de construcción y validación de las instituciones públicas, del derecho público y del derecho público internacional

llarse como individuo en una sociedad. Esta tesis ha sido resaltada por la Corte Constitucional en diferentes oportunidades, cuando ha sostenido que el derecho al mínimo vital no es una garantía cuantitativa, sino cualitativa. Eso significa que, aunque los ingresos de una persona funcionan como criterio para analizar la vulneración del derecho, su protección va mucho más allá. La Corte ha establecido que, a pesar de su estrecha relación, el salario mínimo no es igual al mínimo vital. En efecto, existen situaciones en las que proteger el salario mínimo de una persona no necesariamente garantiza las condiciones básicas sin las cuales un individuo no podría vivir dignamente (República de Colombia, 2013, p. 1).

Las normas del derecho social protegen ese mínimo vital requerido para que las personas cuenten con las condiciones materiales que les permitan llevar una existencia digna. Asimismo, proporcionan seguridad económica a los grupos sociales desprotegidos y protección ante situaciones que vulneren su dignidad, su salud, su integridad física y patrimonial, incluso su vida (Magaña y Sosa, citados en Rosales, 2017, p. 9).

En otras palabras, el mínimo vital consiste en los requerimientos básicos indispensables para asegurar la digna subsistencia de la persona y su familia, no en lo relativo a la alimentación y el vestuario, sino en lo referente a la salud, la educación, la vivienda, la seguridad social y el medioambiente, es decir, en cuanto a los factores insustituibles para la preservación de una calidad de vida que, no obstante su modestia, corresponda a las exigencias más elementales del ser humano (República de Colombia, 1998, p. 1).

Dicho lo anterior, se percibe que en la construcción del Estado-Nación hay un desarrollo mínimo de cultura ciudadana e identidad en los colombianos a la hora de asumirse y configurarse como ciudadanos, ya que no tienen garantías (aunque en casos específicos no reclaman las garantías por falta de reciprocidad en la ley o desinterés). El objeto de esto no es satanizar las relaciones internacionales y el derecho internacional público, sino permitir la crítica a estas instituciones que deben tener un deber, ser cooperativas y solidarias con los países en desigualdad de condiciones, ya que, de lo contrario, incurren en un interés netamente nacional a su beneficio único, en el deterioro, el empobrecimiento y el estancamiento del otro.

Sin embargo, el detalle primordial es mostrar, grosso modo, la importancia que debe tener la configuración social como elemento dinamizador hacia el conocimiento de las instituciones públicas, el derecho público y el derecho internacional público para determinar el porqué de las cosas y qué está bien o mal para el desarrollo del país y sus realidades. 
$\mathrm{Y}$ es que, en temas políticos, Colombia, por su dependencia internacional económica y por sus decisiones, fue adquiriendo saberes externos que le costaron no desarrollar los intereses y los saberes nacionales bajo las realidades propias del territorio y de sus regiones; ${ }^{2}$ adicionando que las divisiones ideológicas y religiosas interiorizadas por la Corona española y el catolicismo asumieron una conducta hostil ante los ciudadanos; esta conducta, posteriormente, daría pie a una gran división: los grandes terratenientes, los comerciantes y los campesinos, que serán un grupo significativo para las nuevas reformas de la época. Por otro lado, los religiosos, los ricos (terratenientes y comerciantes) y la clase media, entre otros, se categorizaron entre liberales y conservadores, respectivamente, emprendiendo guerras internas y fracturas institucionales que impidieron que se diera un proyecto de país para dar paso a un proyecto de intereses particulares.

El efecto producido fue que Colombia tenga diez constituciones desde 1811 a 1991 ("Curiosidades de las constituciones colombianas", 2009), mientras que países más estables del hemisferio americano, como Estados Unidos, solo tengan una desde su conformación. En pocas palabras, no hay una estabilidad en la configuración política en Colombia y, por consiguiente, de las instituciones públicas y del derecho público, ya que no se han sostenido en el tiempo de forma constante y progresiva.

Ocampo (2016) narra que la educación en el hemisferio sur, desde sus inicios, fue apartada de la realidad y de las necesidades del territorio; luego fue minimizada por aspectos ideológicos y religiosos, alejándose del desarrollo nacional y de las competencias de la época, dejando a Colombia sin insumos técnicos y científicos para su avance y para el desarrollo de las instituciones, de los aparatos productivos y de la construcción de ciudadanos.

2 Esto se puede reflejar en un viejo refrán: "Haga lo que le digo, más no lo que hago", pues al ver en política comparada las posturas de libre mercado o las políticas de países desarrollados, en relación con los países subdesarrollados, se ve que en los primeros existe proteccionismo estatal, mientras que en los segundos tiende a privatizarse. Un ejemplo cercano puede ser: "Al decir de George W. Bush: 'es importante para nuestra nación cultivar alimentos, alimentar a nuestra población. ¿Pueden ustedes imaginar un país que no fuera capaz de cultivar alimentos suficientes para alimentar a su población? Sería una nación expuesta a presiones internacionales. Sería una nación vulnerable. Y por eso, cuando hablamos de la agricultura (norte) americana, en realidad hablamos de una cuestión de seguridad nacional'. ¿Utilizó Colombia el mismo concepto de seguridad nacional que, para el efecto, se confunde con el de seguridad alimentaria, para proteger su agro, arguyendo que por las mismas razones que los estadounidenses no eliminaban sus subsidios, los colombianos no eliminarían sus aranceles agropecuarios? Por supuesto que no. Lo que sucedió fue inaudito: el ministro de comercio Jorge Humberto Botero, el representante de Álvaro Uribe Vélez en la 'negociación', corrió a publicar un artículo en el que anunció que el gobierno no esgrimiría el concepto de seguridad alimentaria para defender el agro del país" (La República, 21 de abril de 2004, citado en Robledo, 2006, p. 47). 
La importancia de la pedagogía como herramienta de construcción y validación de las instituciones públicas, del derecho público y del derecho público internacional

En temas sociales, la economía, la política y la educación han influido en la cotidianidad y han interferido en la construcción individual, siendo esta última pobre en insumos y mecanismos institucionales que, a su vez, delimitan y minimizan al individuo en lo organizacional, ya que no hay confianza y legitimidad entre unos y otros debido a esas realidades estratégicas tan débiles y en constante crisis; además, la guerra también ha creado una desconexión con los territorios de Colombia disminuyendo la oferta y la credibilidad institucional. La prueba de esto es que se pueden observar los métodos cuantitativos y cualitativos de la educación en Colombia con base en las pruebas PISA, pues el país ocupó los niveles más bajos del mundo ("Colombia, con la peor nota de la Ocde en pruebas PISA", 2019), confirmando que los que tienen un promedio mayor son los países más desarrollados y pacíficos.

¿Por qué la importancia de lo mencionado anteriormente? Porque es necesario entender que estos temas son constructores de ciudadanía, los cuales pueden ser impulsores o limitadores de opciones y variantes en la vida de las personas y, en consecuencia, de las decisiones del país. Esto se puede comprobar en una fórmula o ecuación infinitesimal en donde todas estas variantes dan un resultado positivo o negativo, en este caso, es negativo, ya que por números y política comparada se puede demostrar que Colombia tiene grandes falencias, como lo expusimos anteriormente, para entender la generalidad y el poder de construir y desarrollar las particularidades de las preguntas.

La síntesis de esto es que la realidad en Colombia es compatible con el arquetipo de María Carmen, una ciudadana que tiene carencia en educación, en saberes económicos y políticos y que habita una sociedad paupérrima que no es capaz de organizarse para poder configurar la estructura estatal como es la democracia representativa y así poder desarrollar las instituciones públicas, el derecho público y el derecho internacional público.

Ya es claro que hay un arquetipo colombiano que sirve de inicio para generar la inquietud de por qué asuntos tan importantes como las instituciones públicas, el derecho público y el derecho internacional son desconocidos. Se sabe que las estructuras no son espontáneas, por el contrario, son una construcción que se da en el tiempo para un fin en concreto (más adelante se expondrá), por eso es importante que de la mano de las instituciones evolucionen y se desarrollen los ciudadanos; por lo tanto, el ciudadano, para la construcción de Estado, debe saber que el conocimiento es un pilar fundamental, y para lograr tal fin, las instituciones deben promover y garantizar un sano desarrollo, tener unas garantías mínimas (económicas y sociales), que con el tiempo maximizan y masifican las capacidades personales y organizativas, y 
un interés manifiesto, por parte de los ciudadanos, hacia las instituciones para conocer la relevancia de estos mecanismos como regidores de vida y generar una práctica constante (compromiso) para incidir en estas.

Entendiendo que dichos mecanismos están ligados al tema político, histórico y económico, Vallés (2007) dice lo siguiente:

Nuestra opción es considerar la política como una práctica o actividad colectiva, que los miembros de una comunidad llevan a cabo. La finalidad de esta actividad es regular los conflictos entre grupos. Y su resultado es la adopción de decisiones que obligan — por la fuerza, si es preciso- a los miembros de la comunidad (p. 18).

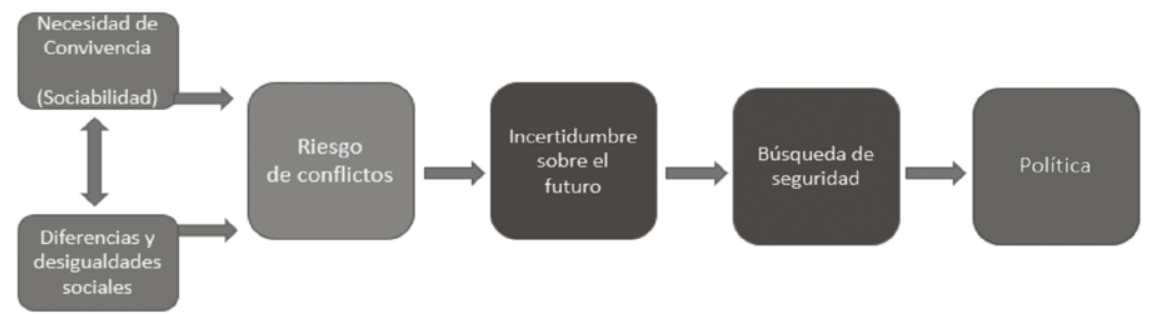

Figura 7.1 La política como garantía de integración social.

Fuente: Vallés (2007, p. 19).

Por esta necesidad, el ser humano comenzó a configurarse en las estructuras sociales y género mecanismos de organización que le permitieron regular, prevenir y mejorar las condiciones de vida.

Entonces, si esa es la realidad y la existencia de estos mecanismos, ¿por qué no se busca ese fin general? Ya lo explicamos anteriormente, y es que la realidad colombiana ha dificultado la construcción del ciudadano. Pues el arquetipo colombiano en sus condiciones materiales, mentales y de oferta institucional no se permite pensarse en mecanismos ni leyes, sino en el hacer diario para sobrevivir, negándoles una realidad distinta a la de vivir en la esperanza de cada cuatro años en los temas electorales del poder ejecutivo. Sin entender que la institución y el derecho público son organismos estatales de reglas/pactos/convenios que existen para conservarse en el tiempo, permitiendo construir programas o proyectos para el mejoramiento de los ciudadanos en función de planificar su vida. 
La importancia de la pedagogía como herramienta de construcción y validación de las instituciones públicas, del derecho público y del derecho público internacional

Para entender dicha afirmación, se debe profundizar en el concepto de Estado, el cual se ha intentado definir por muchos, en este caso "el Estado se entiende como la condición del derecho. El derecho, a su vez, es definido por Kant como el conjunto de condiciones bajo las cuales el arbitrio de uno puede ser compatible con el arbitrio de los otros según una ley general de libertad" (Abellán, 2008, p. 24).

Con esto se demuestra que el Estado de naturaleza, como es concebido en Hobbes, en la modernidad no debe aplicarse, ya que hay motivos como la razón, el comercio, las guerras, entre otros procesos que ha evolucionado en el tiempo de la humanidad como un proceso de aprendizaje y consigo la regulación de estos para que exista paz y mejor calidad de vida, por ende, se configuran mecanismos para que se pueda llegar a esos fines.

Pues el estado de paz es únicamente el estado de lo mío y lo tuyo en una multitud de hombres vecinos entre sí, asegurado bajo leyes que, por consiguiente, están reunidas en una constitución, cuya regla no tiene que ser tomada de la experiencia de los que hasta la fecha se han encontrado mejor con ellas, como una norma para otros, sino tomada por la razón a priori del ideal de una unión jurídica de los hombres bajo leyes públicas en general (Kant, citado en Truyol, 2008, p. 17).

Por ejemplo, Colombia, con la constitución de 1991 y la creación del Estado Social de Derecho, hizo lo que Kant (citado en Truyol, 2008) intuyó en su momento:

La validez de estos derechos innatos, inalienables, que pertenecen al ser humano, queda confirmada y elevada por el principio de las relaciones jurídicas del hombre mismo con entidades más altas (cuando se las representa), al representarse a sí mismo, por esos mismos principios, como un ciudadano de un mundo suprasensible (p. 16),

ya que, si no se generan, "la servidumbre es la muerte de la persona y, sin embargo, es la vida del animal" (Kant, citado en Abellán, 2008, p. 28).

Asunto al que todo ciudadano no quiere llegar y, por ende, busca el estado más puro de la naturaleza en donde "nadie puede obligarme a ser feliz de una cierta manera [...]; cada uno, por el contrario, debe poder buscar su felicidad por el camino que le parece bueno" (Abellán, 2008, p. 28). En el terreno estrictamente político, la libertad significa la "capacidad de obedecer solo a las leyes que he consentido" (Abellán, 2008, p. 28), porque, de lo contrario, no se habla de ciudadano, sino de súbdito. 
Para garantizar dicha situación, los mecanismos son necesarios, pues "la pregunta por los fines del Estado adquiere lógicamente una nueva respuesta, con la que Kant establece una ruptura con la tradición" (Abellán, 2008, p. 25), ya que

había entendido la política, junto a la moral y a la economía, como partes de la filosofía práctica. Estas tres disciplinas tienen en común su preocupación por la vida del hombre: cómo debe vivir y qué condiciones deben darse para que pueda vivir. La categoría central de esa filosofía práctica era la virtud, el bene et honeste vivere (Abellán, 2008, p. 25).

\section{MECANISMOS: INSTITUCIÓN PÚBLICA, DERECHO PÚBLICO Y DERECHO INTERNACIONAL PÚBLICO}

Cuando se piensa en lo anterior, y se hace la radiografía general de la realidad colombiana, se entiende que al existir todos estos insumos expuestos se pueden mitigar las falencias y mejorar la vida de los colombianos utilizando y conociendo los mecanismos que se desarrollan en el texto, sin embargo, una pregunto problematizadora es ¿por qué las personas hablan de otros temas y no de estos mecanismos?

Se puede partir del arquetipo María Carmen, que en resumen tiene dos aspectos: 1) la coacción de su voluntad de forma directa e indirecta por su entorno y la construcción de ciudadanía que propone el territorio llamado Colombia, 2) y el desinterés intrínseco por desconocimiento o falta de acercamiento al área.

Entonces, es importante situarse en la educación, ya que un ciudadano no nace, se construye. No se puede tratar de súbdito o cosa, porque ahí se desvirtúa la naturaleza de dicho Estado. Para ello, Gaviria (2015), en su conferencia del 11 de marzo en el Gimnasio Moderno, en Bogotá, decía: "A las personas no hay que tratarlas como masas amorfas que no inciden en la población, al contrario, hay que enseñarlas a vivir en libertad, y eso es enseñarles a decidir para y por la población".

Lo anterior se desarrolla plenamente en el Estado Social de Derecho por medio de su configuración como democracia representativa, en donde la mayoría de la ciudadanía decide y el Estado debe asumir y garantizar los derechos a todos/as los/as colombianos/as, inclusive si estos son pertenecientes a las minorías. 
La importancia de la pedagogía como herramienta de construcción y validación de las instituciones públicas, del derecho público y del derecho público internacional

Entonces, ¿cuál es el objetivo último de la política?, ¿asegurar la libertad o garantizar la vida? La teoría política se ha planteado a menudo este dilema. Si se entiende que le corresponde asegurar la libertad, no podrá hablarse de la existencia de política en sociedades sometidas al despotismo de un tirano antiguo o de un dictador contemporáneo: el despotismo no sería compatible con la política si se admite que su dominio se funda en la eliminación de las libertades. En cambio, si se admite que la comunidad pretende darse condiciones mínimas para evitar su desintegración - y con ello salvaguardar su existencia-, la política se da tanto en sistemas autoritarios como en regímenes democráticos (Vallés, 2007, p. 21).

¿Qué quiere decir? Dependiendo del horizonte que se tenga, se construyen y se edifican las instituciones públicas y, por lo tanto, sus reglas.

El mundo está evocando a la democracia, sentenciaba Rousseau (2018), y Kant, en su libro Sobre la paz perpetua (2008), decía: "lo que se tenga que demorar se hará". En ese sentido, es importante asumir la Ilustración como esa época continua de construcción a la razón, dando sentido a iluminar (mostrar el camino por medio del razonamiento) a las personas para encarar, reconocer y participar de las estructuras y las instituciones para transformar las realidades; ya que

las instituciones públicas constituyen el conjunto de principios, conocimientos y métodos que nos capacitan idóneamente para lograr la comprensión, simpatía y apoyo del público hacia nuestra organización. Involucra la creación y el mantenimiento de relaciones sanas y productivas con públicos determinados con el fin de estimularlos o influenciarlos a que juzguen favorablemente a una organización, la respeten y le presten apoyo en los momentos de prueba y confusión, ejemplos de estas son: establecimiento, empresa o persona moral fundada con aspiraciones de permanencia cuyos intereses son independientes de los de las personas físicas que la integran, esta es la definición de institución, y pública significa que es de todos y para todos y pagada por todos. Un ejemplo de ello son los colegios públicos, institutos, escuelas infantiles, residencias, hospitales, ministerios, delegaciones, universidades. Se crean para el servicio público, para el fomento cultural, educativo, para beneficiar al pueblo principalmente en aspectos como el de la salud, la seguridad, la capacitación, la legalidad, el orden, etc. Pero la realidad demuestra que se han corrompido quienes dirigen las instituciones y se valen de ellas para enriquecerse, tener poder y mantenerse posicionados (Ruiz, s. f.). 
Estas son funciones del derecho público y del derecho internacional público; el primero de forma nacional y el segundo entre países (naciones) para poder regular, posicionar, mitigar, prevenir, limitar o impulsar las acciones y las relaciones entre la población nacional y las poblaciones internacionales.

Pero ¿qué es el derecho público? "Es una parte de los ordenamientos jurídicos cuyas normas atañen al poder público y sus relaciones con los individuos, las organizaciones y consigo mismos, siempre que este se ejerza como representación de los intereses del Estado" (Raffino, 2020, p. 1).

El derecho público, como se menciona, es una instancia y herramienta humana que se construye y se configura en el tiempo mientras evolucionan las organizaciones sociales que lo involucran, que son de forma consuetudinaria o positiva y que se analizan con base en dos corrientes - que van de la escala nacional-internacional y viceversa-: el monismo y el dualismo. Para entender tal situación, se tiene que ir a la escala del derecho internacional público; esto significa que el derecho internacional público se encarga de estudiar y establecer normas para regular la acción de los Estados y los organismos internacionales, con el propósito de favorecer la cooperación y la negociación como garantías para la paz. Se trata así de una rama del derecho que brinda ordenamiento jurídico a la comunidad internacional.

En ese sentido, la forma de reconocer el derecho público internacional es haciéndolo participe de la realidad nacional, por ende, debe ser ayudado y estimulado desde la academia y desde las universidades para que los ciudadanos aprendan y tengan en su cotidianidad las herramientas y los conocimientos que les permitan legitimar, validar, participar y generar estos mecanismos para el desarrollo del país, y que sean realmente universales para las poblaciones.

\section{¿Cuáles son estos mecanismos?}

Los mecanismos son herramientas de un andamiaje que permite dar funciones precisas sobre un objetivo al que se quiere llegar o lograr. En ese sentido, los mecanismos de las instituciones públicas, del derecho público y del derecho internacional público son los siguientes:

En Colombia se inicia desde la estructura del Estado. Esta estructura es dualista, ya que sus intereses son internacionalistas más que nacionales, en la medida en que los tratados de libre comercio y sus pactos son parte importante para regular sus funciones.

Para entender esto, vamos a mostrar una serie de mapas conceptuales sobre la estructura colombiana y luego nos vamos a lo internacional. 
La importancia de la pedagogía como herramienta de construcción y validación de las instituciones públicas, del derecho público y del derecho público internacional

En la figura 7.2 se detalla la estructura macro del Estado colombiano (instituciones, organizaciones, entre otras):

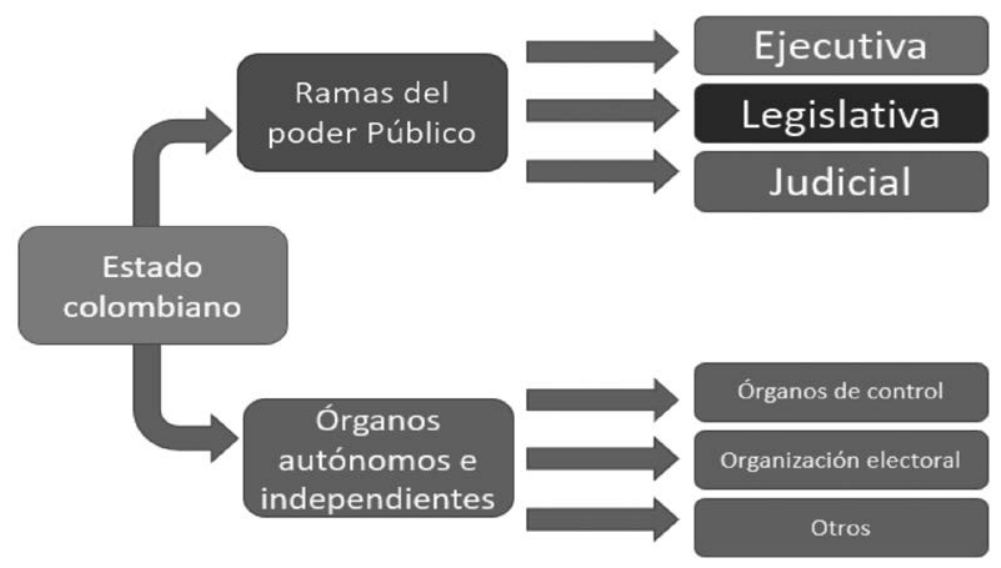

Figura 7.2 Estado colombiano

Fuente: ESAP (2020, p. 5).

La figura anterior representa la forma organizativa que tiene el Estado a la hora de dividir los poderes para prevenir y mejorar el rendimientos de estos en la ejecución, la legislación, la judicialización, la votación o el control sobre estos, los cuales deben guardar autonomía uno de otros, para así conseguir el debido proceso y conservar la funcionalidad que se le ha dado en cada una.

En la figura 7.3 se pueden ver los órganos de control y sus divisiones: 


\section{Órganos de control}

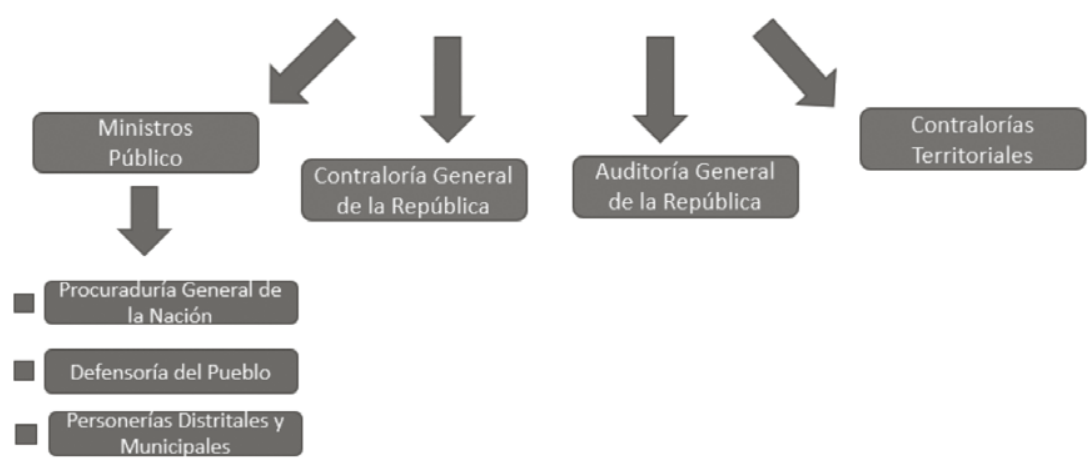

Figura 7.3 Órganos de control Fuente: ESAP (2020, p. 6).

Los órganos de control son independientes a las divisiones del poder, y tienen tareas claras como instituciones, las cuales son: velar por los derechos consagrados en la constitución política y los convenios, y hacer veeduría, control y denuncia en caso de que se incurra en una falta o corrupción en las ramas del poder o en la cotidianidad.

Las tres ramas del poder a las que nos referimos se detallan a continuación. La figura 7.4 hace referencia a la rama judicial.

Esta es una rama del poder, que es la jurídica, y es la encargada de hacer valer y regir las leyes consagradas en la Constitución y el Código Civil. Es decir, en caso de incurrir en falta o corrupción se encarga de establecer el castigo, que es el proceso de judicialización.

La rama ejecutiva (figura 7.5) es la encargada de administrar la economía, la política y la fuerza coercitiva del Estado, y de trazar los planes del país en el tiempo que ha sido electo el presidente de la república, es decir, cuatro años.

La rama legislativa (figura 7.6) es la encargada de elaborar, promover, reformar y derogar las leyes del país; a su vez, está al frente de los proyectos, con base en la constitución que aprueba o rechaza asuntos presidenciales sobre el manejo de políticas. 
La importancia de la pedagogía como herramienta de construcción y validación de las instituciones públicas, del derecho público y del derecho público internacional

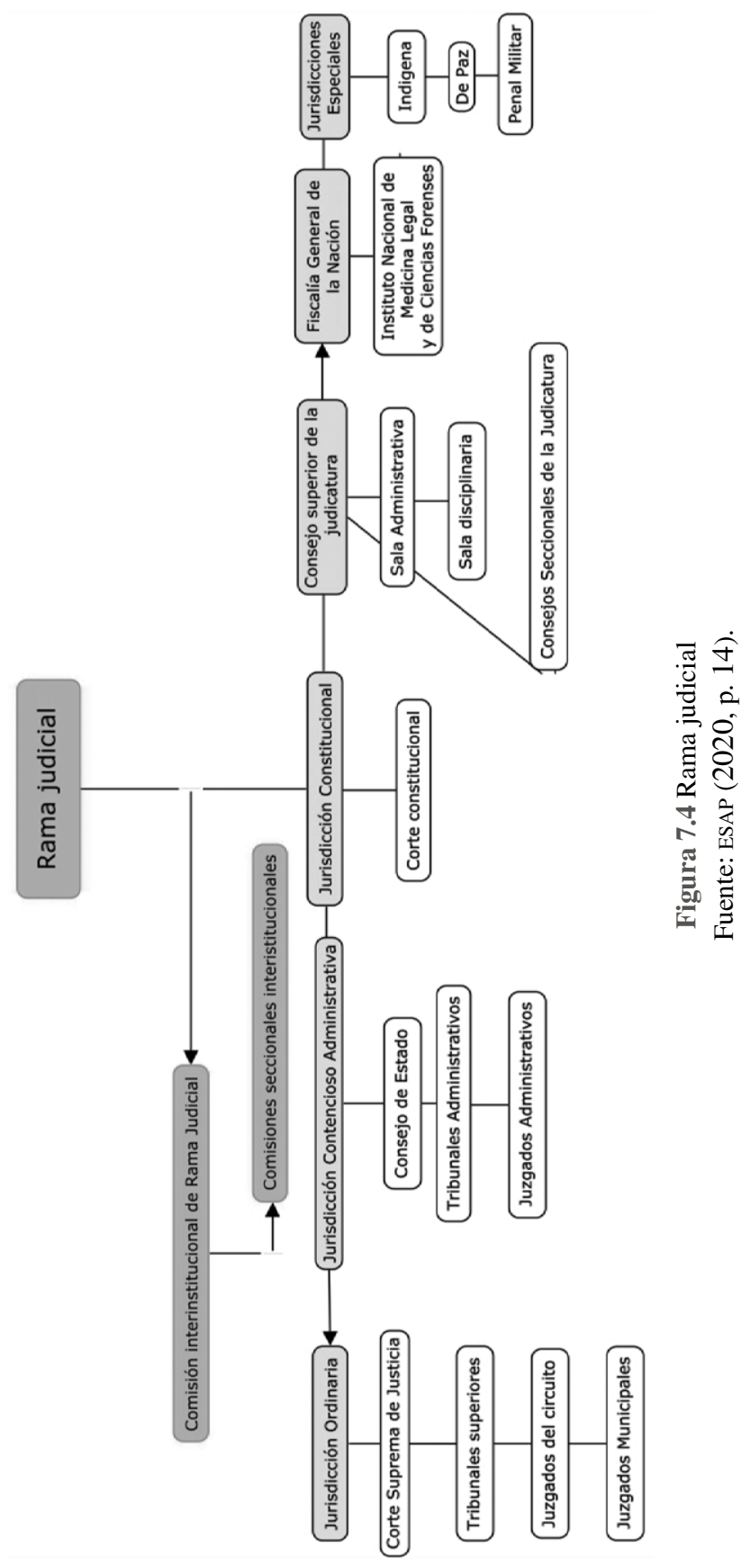




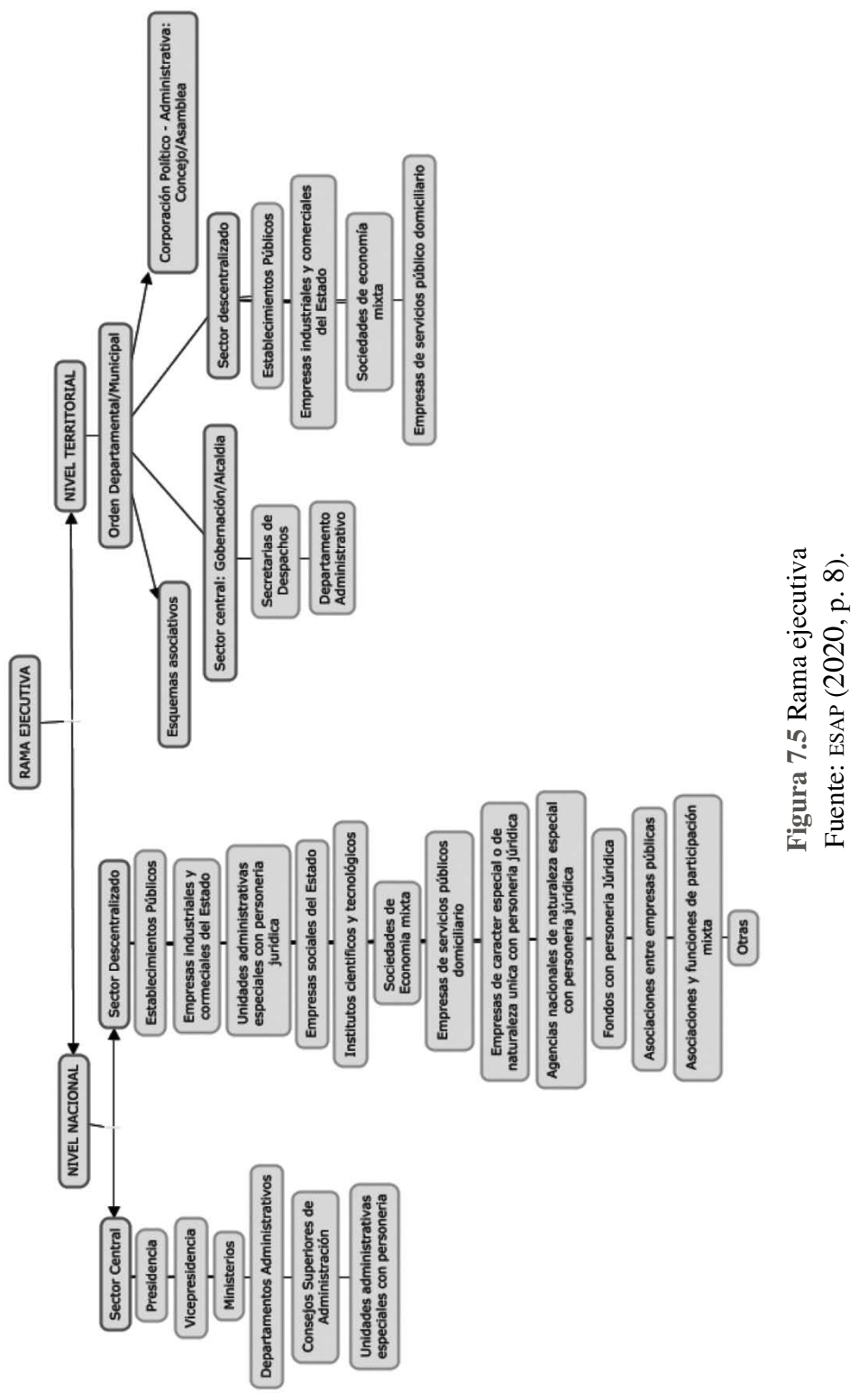




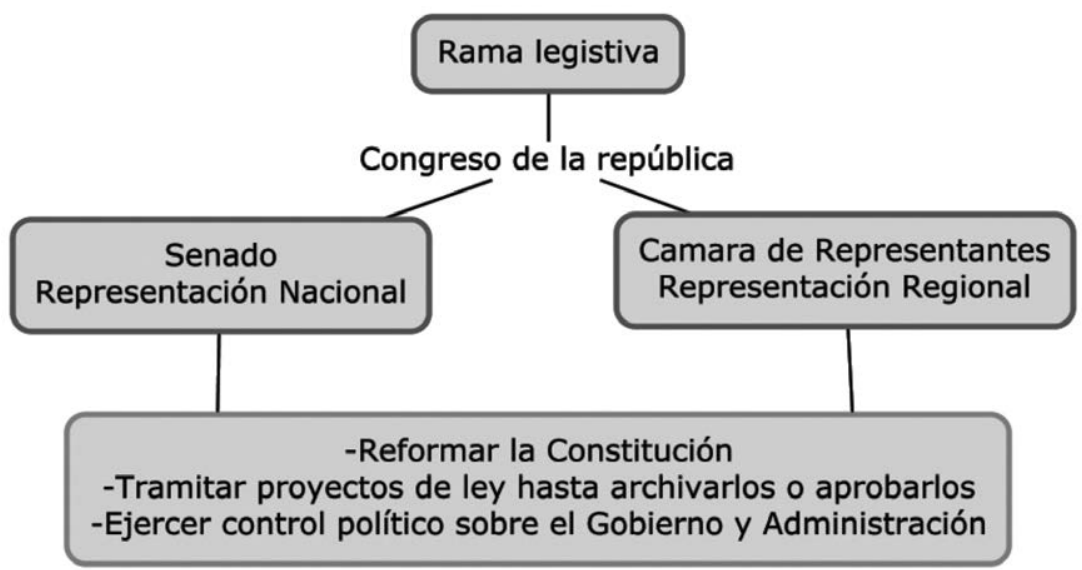

Figura 7.6 Rama legislativa

Fuente: Quimbayo (s. f., p. 1).

Una vez que se observa la composición del Estado colombiano, con sus mecanismos, se va al punto de que hay una información que, en ocasiones, es incomprendida por la generalidad colombiana, es decir, una ciudadanía no formada, ya que la reciprocidad y el desarrollo de dichos mecanismos no son naturales a sus habitantes; en ese sentido, la composición, aunque exista, esté informada y rija la cotidianidad, es incompresible y, por ende, inoperativa. Ese es el reflejo de la realidad que se ha construido.

Esto no cambia en la realidad internacional, por eso, aquí la pregunta es: ¿Cuáles son las instituciones de derecho internacional público? En la figura 7.7 se pueden ver algunas de las más reconocidas e importantes, para que se inicie un proceso de formación. 


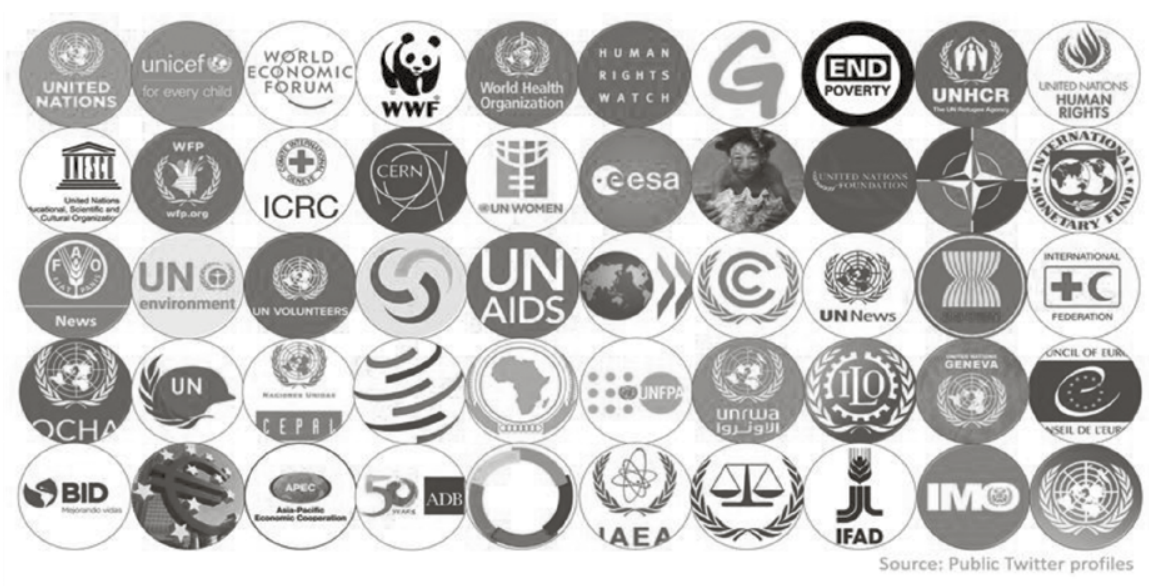

Figura 7.7 Las instituciones internacionales más reconocidas Fuente: “ONU, Unicef y el Foro Económico Mundial, los más seguidos en redes sociales" (2017).

Estas instituciones tienen influencias valiosas dentro de Colombia, en temas económicos, sociales, políticos, educativos y ambientales. Entonces, ¿cómo incide esto en las personas?, pues si se mantiene el enfoque del materialismo sobre las contradicciones y la construcción de conocimiento se puede inferir que las condiciones de dependencia ocasionan que la generalidad de la población las desconozca, ya que el interés del Estado no es fortalecerse, sino al contrario, debilitarse. El texto de Navarro y Fierro (2018) es un ejemplo de eso.

La educación es efecto de la naturaleza, de los hombres o de las cosas. La naturaleza es el desarrollo interno de nuestras facultades y nuestros órganos; la educación de los hombres es el uso que nos enseñan estos a hacer de este desarrollo; y lo que nuestra experiencia propia nos da a conocer acerca de los objetos cuya impresión recibimos, es la educación de las cosas (Rousseau, citado en Urrea, 2010, p. 8).

Por eso la importancia de tomar cartas en el asunto sobre cómo enseñar estos mecanismos. Enseñar no resuelve todo, sin embargo, colabora a que la situación mejore escalonadamente, ya que al fortalecer al ciudadano este fortalece a las instituciones. 
La importancia de la pedagogía como herramienta de construcción y validación de las instituciones públicas, del derecho público y del derecho público internacional

\section{LA PEDAGOGÍA COMO HERRAMIENTA DE CONSTRUCCIÓN Y VALIDACIÓN}

La pedagogía es un menester y una obligación en el asunto de reconocer las realidades de la época y sus procesos para desarrollar un método de enseñanza sobre la materia que se desee de forma asertiva.

Lo mismo que un arquitecto, que observa antes de levantar un gran edificio para ver si puede soportar el peso, así el sabio legislador no comienza por redactar buenas leyes en sí mismas, sino que antes examina si el pueblo al cual las destina es el adecuado para recibirlas (Rousseau, 2018, p. 64).

Esto es lo que se ha estado haciendo, parte de la construcción del pueblo es generar en él un conocimiento abundante y encaminado a la democracia para que pueda ser parte de ese gran proyecto, un territorio hecho para el desarrollo de la democracia y la vida; en consecuencia, la pedagogía como herramienta de construcción y validación es importante, ya que nos permite generar una conciencia y una voluntad hacia un objetivo común.

Rousseau se propone demostrarles a los lectores que la idea de una paz perpetua no es un pensamiento quimérico. "El filósofo ginebrino señala que esta paz no puede lograrse sin una confederación que una a todos los países [...] y que solucione todos los eventuales conflictos entre sus integrantes a través de procedimientos jurídicos justos" (Castro y Elorduy, 2014, p. 41).

Pues las reglas, las normas, los convenios y los pactos tienen un objetivo importante, regular las relaciones entre los individuos $\mathrm{y}$, por consiguiente, a las sociedades. Entendiendo que hay diversidad, pluralidad y conflictos, las relaciones de intereses demuestran hacia dónde se quiere ir; sin embargo, los intereses pueden ser demagógicos ya que pretenden a las particularidades. Entonces, ¿qué exponen los procedimientos jurídicos? Lo que exponen es la coexistencia de toda la diversidad y pluralidad, en tal grado, que se pueda convivir con esas diferencias de forma sana en aras al bien común.

La voluntad general puede dirigir por sí sola las fuerzas del Estado, según el fin de su institución, que es el bien común [...]. El poder es susceptible de ser transmitido, más no la voluntad [...]. Porque la voluntad particular tiende por su naturaleza al privilegio y la voluntad general a la igualdad (Rousseau, 2018, p. 47). 
Y es que la coincidencia que demuestra Rousseau en El contrato social es desenvolver las estructuras sociales en las voluntades, en la forma en que se dirigen las instituciones para afirmar la importancia de la particularidad en la generalidad, debido a que el ciudadano se somete a un ejercicio importante de participación y reconocimiento en la institución, ya que debe vivir dicha premisa, vivir en voluntad general. Es ahí en donde se concibe la idea de la Ilustración, dando como fin la razón para alcanzar la máxima capacidad del ser humano en sociedad, es allí, donde la pedagogía se vuelve elemento indispensable y necesario para que la enseñanza del conocimiento que se desee difundir y aplicar en una sociedad, pueda ser trasmitido y comprendido de la mejor forma.

La importancia de aplicar la pedagogía que se ha expuesto es llegar al fin de validar y construir las instituciones y el derecho que es desconocida por una mayoría en Colombia, permitiendo a su vez, construir una estructura estatal coherente, precisa y operativa al bien común. Es necesario que los ciudadanos sean sujetos de construcción, la educación en Colombia es un ejemplo de la ineficacia y la poca operatividad, incluso, las condiciones de los jóvenes para ingresar a la educación de calidad se dificultan al punto que es inaccesible para la mayoría.

Coincidiendo en dos aspectos, la economía delimitó a ciertas clases para adentrarse en su tiempo de ocio, desarrollar sus aptitudes y hacer uso de la educación como referente deliberativo para la construcción de vida, como se puede leer en Rousseau (2018) y luego en Kant (2008), explicando la importancia de la razón como pilar fundamental de la obtención de intereses consecutivos a la funcionalidad de una estructura social como la democracia y las instituciones.

Ahora, ¿qué se puede hacer al respecto para que el colombiano se transforme en un verdadero ciudadano?

Para iniciar, es necesario concebir a las instituciones y al derecho público como organismos vivos y mecánicos que permiten dar unas reglas y funcionalidades a las relaciones humanas; sin embargo, hay que reconocer que la institucionalidad evoluciona en el tiempo, por ende, no es espontánea ni sus reglas ni su funcionalidad, es por esto que se fundamenta en unos saberes ya adquiridos por la experiencia social.

Cuando el ciudadano reconoce las instituciones y el derecho público, se permite a su vez conocerlos y apropiarse de estos, ya que esta apropiación e identidad hará que tengan una aceptación y progresivamente una vinculación, generando la necesidad de ser descubiertos y requeridos por la cotidianidad, ya que esto, implícita y explícitamente, tiene una carga positiva en mejorar el relacionamiento entre las personas, y en una escala mayor, entre países. 
La importancia de la pedagogía como herramienta de construcción y validación de las instituciones públicas, del derecho público y del derecho público internacional

En ese sentido, el Estado debe ser un amigo y mentor de cada individuo y generar una comunicación acertada y estratégica que permita validar y construir una ciudad que satisfaga las necesidades de la generalidad.

En la comunicación con el amigo invisible sentía yo el más dulce goce de todas mis energías vitales. El ansia de gozar cada vez más ese placer era tan grande, que de buen grado suprimía yo cuanto a ese placer se oponía, y en este particular era la experiencia mi mejor maestro el trato con el amigo invisible sentía el más dulce goce de todas las fuerzas de mi vida (Goethe, citado en Urrea, 2010, p. 10).

Por lo tanto, si se desean construir los mecanismos se debe ser consecuente con estos.

Pensar y obrar, obrar y pensar, es la suma de toda sabiduría, en todo tiempo reconocida, en todo tiempo practicada, pero no por todos advertida. Una y otra cosa ha de alternar eternamente en la vida, como la inspiración y la expiración; debían ser inseparables como la pregunta y la respuesta. Quien se hace una ley de lo que el genio de la razón humana susurra secretamente al oído de cada recién nacido, es decir, somete la acción al examen del pensar y el pensar al examen del hacer, este no puede equivocarse nunca y, si se equivoca, encontrará pronto el buen camino (Goethe, citado en Urrea, 2010, p. 10).

Además, como lo dijo Gaviria (2015) a las personas no hay que tratarlas como masas amorfas que inciden en la población, por el contrario, hay que enseñarles a vivir en libertad y eso es enseñarles a decidir. Cuando se comienza a enseñar, a pensar y a obrar es cuando se cambia el paradigma de las particularidades evocando las personas a ser parte de las instituciones y los derechos.

Ya que "la guerra no es, pues, una relación de hombre a hombre, sino una relación de Estado a Estado" (Rousseau, 2018, p. 35), se puede conformar el estado de guerra o de paz, dependiendo de los intereses del ciudadano. Conformar un Estado para perpetuar el poder de decidir, y que este, a su vez, ejerza control y regulación sobre las instituciones. Para poder obrar en dichas instancias hay que conocerlas para lograr que funcionen de forma correcta, dando así la garantía de los deberes y derechos a cualquier persona y país, dejando claro el estado que se busca, en este caso es el de paz. 
En ese sentido, la ciencia tiene la capacidad de cambiar a la humanidad; sin embargo, si la percepción humana no lo permite, esta de nada sirve; de ahí debemos partir. Ya hay unos insumos que se han ido señalando para avanzar en esa tarea, pero es importante entender que la pedagogía es parte de esa naturaleza que percibimos externamente y que transformamos en realidad y experiencia propia ante la relación entre las personas y el entorno.

Por esa razón, hay que llevar esa ciencia a la gente, a las personas de a pie, para que entiendan que la política y el derecho buscan regular las relaciones humanas, y eso coincide con sus estructuras mínimas hasta las superestructuras. De ahí la importancia de participar en ellas y de generar procesos evolutivos que descifren las necesidades para satisfacer las estructuras, pues al fin y al cabo son configuraciones humanas que tienen ese fin de dar orden a la vida, ese derecho de vivir o morir, pero ¿en qué circunstancias? esa es la pregunta.

El estado de violencia jamás cambiaría únicamente por la naturaleza del asunto y sin apoyarse en el arte político [...]. Como los más poderosos no tienen ninguna razón de jugar ni los más débiles ninguna esperanza de beneficio, es bueno para todos que renuncien a lo que desean para asegurar lo que poseen (Rousseau, citado en Castro y Elorduy, 2014, p. 46)

En consecuencia, la razón es la forma de generar y de edificar las verdaderas instituciones y los derechos que comulguen las necesidades y las funciones de los individuos y los Estados.

Un Estado no es, por supuesto, un patrimonio (patrimonium) (como el suelo sobre el que tiene su sede). Es una sociedad de seres humanos sobre la que nadie más que él mismo tiene que mandar y disponer. Injertarlo artificialmente en otro Estado, a él que como un tronco tiene sus propias raíces, significa eliminar su existencia como persona moral y convertirlo en una cosa, contradiciendo, por tanto, la idea del contrato originario sin el que no puede pensarse ningún derecho sobre un pueblo [...]. Pero la razón práctica nos prohíbe acelerar este desarrollo mediante el empleo de medios no legítimos. Dicho de otra forma: el mero cálculo estratégico no puede cumplir la tarea de proveernos de medios justos para alcanzar un fin moral (Castro y Elorduy, 2014, p. 55). 
La importancia de la pedagogía como herramienta de construcción y validación de las instituciones públicas, del derecho público y del derecho público internacional

Y es que la construcción del Estado es una tarea constante para formar y fortalecer a los ciudadanos, "Kant está consciente de que la aproximación a la paz perpetua no podrá llevarse a cabo sino gradualmente. Esto significa, entre otras cosas, que no es posible determinar de antemano el tiempo que tomará la realización de esta tarea" (Castro y Elorduy, 2014, p. 56), cuyo ejercicio debe ser público para que sea de interés general y pueda darse una voluntad general.

Toda pretensión jurídica debe poseer esta capacidad de ser hecha pública y la publicidad puede, por ello, suministrar un criterio a priori de la razón, de fácil empleo, para conocer inmediatamente, como por un experimento de la razón pura, la falsedad (ilegalidad) de la pretensión (pretensio iuris) en el caso de que no se dé la publicidad, ya que resulta muy fácil reconocer si se da en un caso concreto, es decir, si la publicidad puede ser compatible o no con los principios del agente (AA, VIII: 381) (Castro y Elorduy, 2014, p. 41).

$\mathrm{Y}$ es que cuando se saben hacer (se reconoce la materia u objeto), las acciones, las estructuras y los proyectos se encaminan al éxito. Por tal motivo, la información y la enseñanza (pedagogía) deben ser mutuas, para que la razón se dé.

Todo esto de forma pública, ya que los contratantes, es decir, los ciudadanos, al asumir un compromiso, su legitimidad y buena fe se da bajo el criterio de la transparencia y su constante evolución en la difusión de lo pactado. 


\section{CONCLUSIONES}

Para concluir el artículo, se tiene claro que el arquetipo colombiano es una construcción histórica, social, económica, política y educativa; la importancia del esbozo de María Carmen es notorio, como un primer indicio de cómo se da esa generalidad colombiana. Esa generalidad analfabeta política, sin recursos y sin medios para poder participar en las instituciones públicas, el derecho público y el derecho público internacional. Dichas instancias permiten tener unas reglas de juego y configuraciones sociales con base en los intereses que desea la ciudadanía de los territorios nacionales o entre los países.

De ahí la importancia de que sean analizados simultáneamente a la luz del contexto material del fenómeno colombiano, ya que toda configuración social es una construcción constante del individuo en el entorno de su tiempo y espacio.

En ese sentido, la exposición de toda esa construcción material y de conciencia permite conocer y reconocer unas pautas transversales como la academia y la pedagogía, considerándose herramientas de validación y construcción para que los ciudadanos se apropien de dichas instituciones y derechos que garantizan un mejoramiento de vida para sí mismos y para su entorno.

Dicho lo anterior, se tomaron fuentes valiosas de los distintos pensadores, encuestas, periódicos y sentencias constitucionales para demostrar que hay un sistema elaborado para el funcionamiento estatal. Este funcionamiento genera inquietudes para la reflexión, lo que posibilita la identificación de las experiencias de un territorio; mientras que se desarrolla el punto central del trabajo que son las instituciones y el derecho público que rigen las condiciones de vida de los ciudadanos de forma positiva o negativa.

Por tal motivo, es importante resaltar la necesidad expuesta en este artículo de universalizar, contextualizar, conocer, descubrir y transmitir los saberes a esa gran mayoría que representa María Carmen y la encuesta de CELAG.

Reconocer los tópicos mencionados anteriormente permite generar un panorama amplio de las instituciones y del derecho público que expone un interés en el territorio, sea este intervenido por un ente externo o no. Es ahí donde la razón entra en función, ya que la ciudadanía solo se da mientras esta se asuma, se conozca y se represente en ese contrato llamado Estado-nación. 
La importancia de la pedagogía como herramienta de construcción y validación de las instituciones públicas, del derecho público y del derecho público internacional

\section{REFERENCIAS}

Abellán, J. (2008). Sobre el concepto de República. En I. Kant (2008), Sobre la paz perpetua (págs. 1-11). Tecnos.

Aristóteles (1996). La política. Alba Editorial.

Castro, D. y Elorduy, E. (2014). El ideal de la paz perpetua en Rousseau y Kant. Signos Filosóficos, 16(31), 37-62.

Colombia, con la peor nota de la Ocde en pruebas PISA (2019). Portafolio. https://www.portafolio.co/economia/colombia-con-la-peor-nota-dela-ocde-en-pruebas-pisa-536148.

Curiosidades de las constituciones colombianas (2009). Portafolio. https://blogs.portafolio.co/juridica/curiosidades-de-las-constituciones-colombianas/\#: : text=Cantidad\%20de $\% 20$ Constituciones $\% 20$ Nacionales\%3A\%20Colombia,una\%20(61)\%20constituciones\%20provinciales.

Escuela Superiro de Administración Pública (ESAP) (2020). Estructura del estado y mecanismos de participación ciudadana. https://www.studocu. $\mathrm{com} / \mathrm{co} /$ document/universidad-de-santander/biomecanica/apuntes/m1-estructura-del-estado-y-mecanismos-de-participacion-ciudadana/11759624/view.

Gaviria, C. (2003). La ciudadana María del Carmen Reyes. El Tiempo. https://www.eltiempo.com/archivo/documento/MAM-1009871.

Gaviria, C. (2015). Educar para la democracia [conferencia]. Bogotá. Harari, Y. (2014). De animales a dioses. Debate.

Kant, I. (2008). Sobre la paz perpetua. Tecnos.

Melo, J. O. (2017). Historia mínima de Colombia. El Colegio de México.

Navarro, O. y Fierro, A. (2018). Focus Group Colombia. https:// www.celag.org/colombia-elecciones-presidenciales-2018-estudio-cualitativo-de-opinion/.

Ocampo, J. (2013). Colombia siglo XX. Tercer Mundo.

Ocampo, J. (2016). La educación: de la colonia al siglo XX. Confrontaciones ideológicas y políticas. Ediciones Aurora.

ONU, Unicef y el Foro Económico Mundial, los más seguidos en redes sociales (2017). LatinSpots.

http://www.latinspots.com/sp/empresas-y-negocios/detalle/18514/onuunicef-y-el-foro-econmico-mundial-los-ms-seguidos-en-redes-sociales.

Quimbayo, J. (s. f.). Estado colombiano. https://cienciassocialestic. wordpress.com/regiones-naturales-de-colombia/.

Raffino, M. (2020). Derecho público. Concepto de. https://concepto. de/derecho-publico/. 
República de Colombia (1998). Corte Constitucional. Sentencia T-011 de 1998. https://www.corteconstitucional.gov.co/relatoria/1998/T-011-98.htm.

República de Colombia (2013). Corte Constitucional. Sentencia T-891 de 2013. https://www.corteconstitucional.gov.co/relatoria/2013/T-891-13.htm.

Robledo, J. (2017). El TLC recoloniza a Colombia. Acusación a Álvaro Uribe Vélez. TR Ediciones.

Rodríguez, M. A., Fonnegra, G. y Alemán, C. (2019). Textos clásicos del marxismo. En J. Stalin (1977), Sobre el materialismo dialéctico y el materialismo histórico (págs. 165-201). EHK.

Rosales, C. M. (2017). El mínimo vital como institución de justicia elemental. Revista Jurídica IUS Doctrina, 10(2).

Rosental, M. y Iudin, P. (1959). Diccionario filosófico abreviado. Pueblos Unidos.

Rousseau, J. (2018). El contrato social. Comcosur.

Ruiz, L. (s. f). Instituciones públicas y privadas. https://sites.google.com/site/historiacecytemcuautitlan/segundoparcial/institucionespublicasyprivadas.

Stalin, J. (1977). Sobre el materialismo dialéctico y el materialismo histórico. EHK.

Truyol, A. (2008). Presentación. I. Kant (2008), Sobre la paz perpetua (págs. 1 - 14). Tecnos.

Urrea, W. (2010). La concepción pedagógica en Rousseau y Goethe. Itinerario Educativo, 24(55), 145-158.

Vallés, J. (2007). Ciencia política. Una introducción. Ariel. 